\title{
ANALISIS RASIO KEUANGAN YANG BERPENGARUH TERHADAP NPL BANK SWASTA NASIONAL
}

\author{
Liviawati $^{1}$; Gusmarila Eka Putri ${ }^{2}$; Jeni Wardi ${ }^{3}$ \\ Fakultas Ekonomi Universitas Lancang Kuning \\ Jln. D.I. Panjaitan KM 8 Rumbai Pekanbaru \\ E-mail : gusmarilaputri@unilak.ac.id \\ diterima: 17/1/2021; direvisi: 3/4/2021; diterbitkan: 26/9/2021
}

\begin{abstract}
Generally, credit interest income is a source of income that banks in Indonesia rely on as the main income in financing their operations. Loans provided by banks are guaranteed by collateral, but if the credit is to be detrimental to the banking sector where the banking sector will experience losses in the form of not generating interest income, a more fatal loss is the existence of other expenses that will be issued by the bank in an attempt to disburse these funds and lost time.

The high and low quality of the credit provided will give a bank's NPL ratio. The higher the NPL, the lower the credit quality, meaning the lower the collectibility of the credit and vice versa. The high NPL also disrupts the level of operational efficiency of the bank which in turn will disrupt the bank's ability to generate profits (profitability). Therefore, the banking sector really needs to pay attention to this NPL. The purpose of this study is to examine the factors that influence NPL in private banks, case studies on national private banks.
\end{abstract}

Keywords: Financial Ratio, NPL, National Private Banks

\section{PENDAHULUAN}

Bank adalah lembaga keuangan yang menghimpun dana dari masyarakat dan kemudian mendistribusikannya kembali kepada masyarakat yang membutuhkan dana. Masyarakat yang menaruh dananya diperbankan akan diberi pendapatan berupa bunga yang jika dipandang dari sisinya banknya adalah beban bunga dan masyarakat yang meminjam dana yang dihimpun bank tadi akan dikenakan bunga oleh bank, dari sisi bank itu merupakan pendapatan. Pendapatan bunga bank diperoleh dari selisihnya. Oleh karena itu maka perbankan harus benar-benar berhati-hati dalam mengelola pinjaman agar pendapatan bisa diperoleh dan dana yang sudah diberikan dalam bentuk pinjaman bisa diterima kembali oleh bank dan dapat didistribusikan kembali kepada pihak yang deficit dana.

Pinjaman yang diberikan oleh bank memang dijamin oleh agunan, akan tetapi jika pinjaman itu sudah macet hal ini akan merugikan pihak perbankan dimana pihak perbankan akan mengalami kerugian berupa tidak dihasilkannya pendapatan bunga, kerugian yang lebih fatal lagi adalah adanya beban-beban lain yang akan dikeluarkan oleh bank dalam usaha mencairkan agunan tersebut serta rugi waktu.

Tinggi rendahnya kualitas pinjaman yang diberikan itu akan tercermin di rasio NPL suatu bank. Semakin tinggi nilai NPL mengindikasikan bahwa kualitas pinjamannya semakin rendah artinya tingkat collectibilitas pinjamannya semakin rendah. Berlaku sebaliknya, semakin rendah nilai rasio NPL nya itu berarti kualitas pinjamannya semakin tinggi artinya tingkat collectibilitas pinjamannya semakin tinggi ( bagus ) atau boleh disimpulkan tak ada kredit atau pinjaman yang bermasalah. Tinggi rendahnya NPL ini juga mengganggu tingkat efisiensi dari operasional bank tersebut yang pada akhirnya akan mengganggu kepada kemampuan bank dalam menghasilkan laba ( profitabilitas ). Oleh sebab itu pihak perbankan sangat perlu untuk memperhatikan NPL ini. 
Dahlan Siamat ( 2004 ; 92 ) mengungkapkan resiko kredit adalah suatu resiko yang diperoleh bank ketika nasabah gagal mengembalikan jumlah pinjaman berikut bunganya. Ketidakmampuan nasabah mengembalikan pinjaman akan mengakibatkan kerugian bagi perbankan dimana kerugian ini akan dibebankan pada cadangan sedangkan cadangan ini mempunyai nilai terbatas yang pada akhirnya akan mengurangi modal bank itu sendiri .

Bank Indonesia dalam peraturannya menetapkan batas toleransi kredit bermasalah sebesar lima persen dengan perhitungan jumlah kredit bermasalah dibagi dengan total kredit.

\section{TINJAUAN PUSTAKA}

Aktivitas perkreditan merupakan tulang punggung atau kegiatan utama bank.kredit yang disalurkan oleh bank, merupakan bagian asset terbesar yang dimiliki oleh bank, dalam kondisi perekonomian yang normal kredit dapat mencapai 70\%-90\% dari asset bank.

Simorangkir menyatakan kriteria kredit berkualitas atau tidak (2004) sebagai berikut : (1) Lancar , (2) Dalam perhatian khusus, (3) Kurang lancar (4) Diragukan dan (5) Macet

Likuiditas adalah rasio yang digunakan untuk mengukur kemampuan bank untuk memenuhi kewajiban lancarnya dengan memakai rasio LDR (membandingkan jumlah kredit yang diberikan bank dengan dana nasabah yang diterima bank). Modal (CAR) Yaitu rasio untuk mengukur kecukupan modal yang dimiliki bank untuk menunjang aset yang mengandung resiko, contoh, kredit yang diberikan. Resiko, dengan memberikan kredit, bank berhadapan dengan resiko yaitu tunggakan kredit dari nasabah, oleh sebab itu kredit yang menunggak itu memerlukan kebijakan dan penyelesaian yang tepat dan efektif. Bank Indonesia dengan peraturannya memberikan batas toleransi rasio kredit bermasalah ( NPL ) adalah sebesar 5 persen. Net interest Margin ( NIM ), Rasio ini mengukur kemampuan manajemen bank dalam mengelola asset produktif untuk memperoleh pendapatan bunga bersih. Rasio ini diperoleh dengan membagi pendapatan bunga bersih dan average productive asset. Beban Operasional terhadap Pendapatan operasional ( BOPO ) Rasio ini diperoleh dari biaya operasional dibagi pendapatan operasional. BOPO diukur dengan tingkat efisiensi dan kemampuan bank dalam melakukan kegiatan operasinya. Semakin kecil rasio ini berarti semakin efisien biaya operasional yang dikeluarkan bank tersebut. BOPO ditetapkan dibawah $90 \%$ oleh BI. Ukuran perusahaan, Ukuran perusahaan dihitung dari total harta yang dimiliki perusahaan . Menurut sastradiputra (2004), sisi asset pada bank menunjukkan strategi dan kegiatan manajemen yang berkaitan dengan tempat pengumpulan dan meliputi kas, rekening pada bank sentral, pinjaman jangka pendek dan jangka panjang dan asset tetap

\section{Hipotesis Penelitian}

\begin{tabular}{lll}
\hline H1 & $:$ & $\begin{array}{l}\text { Modal (CAR) berpengaruh terhadap } \\
\text { NPL bank swasta nasional }\end{array}$ \\
\hline H2 & $:$ & $\begin{array}{l}\text { Likuiditas (LDR) berpengaruh terhadap } \\
\text { NPL bank swasta nasional }\end{array}$ \\
H3 : & $\begin{array}{l}\text { BOPO berpengaruh terhadap NPL bank } \\
\text { swasta nasional. }\end{array}$ \\
H4 : & $\begin{array}{l}\text { Ukuran perusahaan berpengaruh } \\
\text { terhadap NPL bank swasta nasional. }\end{array}$ \\
H5 $:$ & $\begin{array}{l}\text { Tingkat suku bungan SBI berpengaruh } \\
\text { terhadap NPL bank swasta nasional }\end{array}$ \\
H6 : $\begin{array}{l}\text { Daya beli berpengaruh terhadap NPL } \\
\text { bank swasta nasional }\end{array}$ \\
H7 : $\begin{array}{l}\text { Tingkat inflasi berpengaruh terhadap } \\
\text { bank swasta nasional }\end{array}$ \\
H8 & $\begin{array}{l}\text { CAR,LDR,BOPO,ukuran perusahaan, } \\
\text { suku bunga SBI,daya beli dan tingkat } \\
\text { inflasi berpengaruh terhadap NPL bank } \\
\text { swasta nasional }\end{array}$ \\
\hline
\end{tabular}

\section{METODE PENELITIAN}

Objek dalam penelitian ini yaitu laporan keuangan bank swasta yang listing di BEI. Populasinya adalah bank swasta yang terdaftar di BEI. Sedangkan 
sampel penelitian adalah bank swasta dengan ketentuan sebagai berikut: (a) Bank swasta yang tidak mengalami laba negatif dari tahun 2010 sampai 2019 , (b) Bank swasta yang memiliki kelengkapan data seperti yang dibutuhkan dalam penelitian ini dan (c) Bank swasta yang bukan merupakan hasil merger atau penggabungan usaha

Teknik pengambilan sampelnya menggunakan teknik purposive sampling. Sumber data yang digunakan adalah sekunder yaitu data yang diperoleh melalui website www.idx.co.id

Analisis data yang digunakan adalah analisa regresi berganda. Dan persamaan regresi yang di gunakan adalah sebagai berikut:

$\mathrm{Y}=\mathrm{B}+\mathrm{B} 1 \mathrm{X} 1+\mathrm{B} 2 \mathrm{X} 2+\mathrm{B} 3 \mathrm{X} 3+$ $\mathrm{B} 4 \mathrm{X} 4+\mathrm{B} 5 \mathrm{X} 5+\ldots \ldots+\mathrm{e}$.

\section{HASIL DAN PEMBAHASAN}

Dari tabel statistik dapat dijelaskan bahwa rata-rata NPL 8 bank papan atas yaitu bank BCA,Panin, mega , permata, BTPN, cimb niaga dan ocbc nisp adalah 2,399\% yang berarti lebih rendah dari ketentuan maksimum yang disyaratkan oleh BI yaitu $5 \%$ sedangkan rata -rata CAR 8 bank diatas yaitu 18,98\%. Rata-rata Likuiditas ( LDR) 8 bank diatas pada level $91,78 \%$ masih dibawah batas aman yang diisyaratkan oleh bank indonesia sebesar 92\% sedangkan rata-rata BOPO ke delapan bank diatas yaitu $80,28 \%$ masih dibawah batas BOPO yang disyaratkan oleh BI yaitu $90 \%$. Rata-rata inflasi dari tahun 2014 sampai dengan 2019 yaitu 4,16\%, rata-rata tingkat bunga sertifikat BI adalah $6,3 \%$.

Dari hasil uji regresi terbukti CAR berpengaruh terhadap NPL bank swasta nasional yang ditandai dengan nilai signifikan $0,002<$ dari 0,05 artinya bahwa H0 ditolak dan $\mathrm{H} 1$ diterima. Pengaruh CAR terhadap NPL berpengaruh positif.
Berdasarkan hasil uji regresi terlihat bahwa LDR berpengaruh terhadap NPL bank swasta nasional yang ditandai dengan nilai signifikan0,041 < dari 005 artinya $\mathrm{H} 0$ ditolak dan $\mathrm{H} 2$ diterima. Pengaruh LDR terhadap NPL adalah negatif yang artinya jika NPL naik maka LDR turun dan berlaku sebaliknya

Berdasarkan hasil uji regresi terbukti BOPO memiliki pengaruh pada NPL bank swasta nasional yang ditandai dengan nilai signifikan $0,000<$ dari 0,05 , artinya $\mathrm{H} 0$ ditolak dan $\mathrm{H} 3$ diterima. Pengaruh BOPO terhadap NPL bersifat positif artinya jika NPL naik maka BOPO pun akan naik. BOPO adalah untuk mengukur efisiensi operasional dari suatu bank

Berdasarkan hasil uji regresi dapat dinyatakan bahwa ukuran perusahaan berpengaruh terhadap NPL yang ditandai dengan nilai signifikan 0.05.

Berdasarkan hasil uji regresi dapat dinyatakan bahwa tingkat suku bunga sertifikat bank Indonesia tidak berpengaruh terhadap NPL yang ditandai dengan nilai signifikan $0.455>0,05$.

Berdasarkan hasil uji regresi dapat dinyatakan bahwa daya beli tidak berpengaruh terhadap NPL yang ditandai dengan nilai signifikan $0.568>0,05$. Daya beli dihitung dengan pendapatan perkapita bruto

Berdasarkan hasil uji regresi dapat dinyatakan bahwa inflasi tidak berpengaruh terhadap NPL yang ditandai dengan nilai signifikan $0.467>0,05$.

Berdasarkan hasil uji $F$ diatas maka terlihat bahwa CAR, LDR, BOPO, ukuran perusahaan, Inflasi, SBI dan GDP berpengaruh terhadap NPL yang ditandai dengan nilai signifikan $0,00<0,05$.

Berdasarkan hasil uji statistik disimpulkan bahwa CAR berpengaruh terhadap NPL dimana pengaruhnya bersifat positif artinya jika NPL suatu perbankan naik maka modal yang harus disediakan perbankan tersebut juga harus naik agar dapat menutupi kerugian dan 
Jurnal Ilmiah Ekonomi dan Bisnis

Vol. 18. No.2,September 2021 : 183-188

EISSN : $2442-9813$

ISSN : $1829-9822$

menjamin likuiditas perbankan yang disebabkan oleh adanya kredit yang bermasalah. Hasil penelitian ini sejalan dengan hasil penelitian yang dilakukan oleh Suli Astrini,I wayan Suwendra dan ketut suwarna

Berdasarkan hasil uji regresi maka dapat disimpulkan bahwa LDR berpengaruh terhadap NPL dimana pengaruhnya negatif. Hal ini dapat dijelaskan bahwa Jika NPL naik mengindikasikan bahwa kualitas kredit yang diberikan pada nasabah itu jelek artinya banyak kredit yang macet. Akibat dari banyak kredit yang macet maka hal ini akan mengganggu likuiditas perbankan. Dana yang diberikan kepada nasabah yang meminjam adalah dana yang diperoleh dari nasabah yang menabung atau mendepositkan uang di bank jika uang yang telah disalurkan menjadi kredit terlambat atau macet dibayar oleh nasabah maka jika nasabah mau mengambil uang yang didepositkannya bank akan susah mencairkannya karena uang masih ditangan nasabah yang meminjam uang. Hasil penelitian ini sejalan dengan penelitian Andreani Caroline barus yang berjudul Analisis Faktor yang Mempengaruhi NPL pada Bank umum di Indonesia

Berdasarkan hasil uji regresi terbukti BOPO memiliki pengaruh pada NPL. Hal ini berarti jika NPL meningkat maka BOPO pun naik artinya jika banyak kredit yang bermasalah akan mengakibatkan bank beroperasi tidak efisien lagi.Hal ini sejalan dengan hasil penelitian yang dilakukan oleh Lia Ryzkita dan M.Jusmansyah. Penelitiannya pada 20 bank swasta nasional dari tahun 2007 sampai dengan 2010 .

Berdasarkan hasil regresi terbukti bahwa ukuran perusahaan berpengaruh terhadap NPL hal ini bisa dijelaskan bahwa pada ukuran bank yang besar nasabah kreditnya nasabah yang memiliki perusahaan besar yang memiliki pinjaman yang besar pula jadi jika perbankan yang besar tidak pandaipandai memilih nasabah kredit maka kredit bermasalah pada bank yang ukuran besar akan besar pula. Hasil penelitian ini sejalan dengan hasil penelitian Andreani Caroline barus yang berjudul Analisis Faktor yang Mempengaruhi NPL pada Bank umum di Indonesia.

Berdasarkan hasil terlihat bahwa tingkat bunga SBI tidak berpengaruh terhadap NPL. Hal ini bisa dijelaskan bahwa tingkat bunga SBI hanya sebagai salah satu acuan untuk menentukan bunga kredit ditambah dengan biaya lain yang sehubungan dengan kredit.Hasil penelitian ini sejalan dengan hasil penelitian Ariq fikriq Niagasi yang berjudul pengaruah LDR,Ukuran perusahaan, BI rate danExchange rate terhadap NPL. Dimana hasilnya LDR berpengaruh terhadap NPL sedangkan variabel lain tidak berpengaruh terhadap NPL.

Berdasarkan hasil regresi terlihat bahwa Daya beli tidak berpengaruh terhadap NPL. Hal ini bisa dijelaskan bahwa daya beli merupakan indikator untuk mengukur kemampuan masyarakat untuk membeli barang dan jasa. Jika daya beli turun maka diartikan bahwa kemampuan masyarakat untuk membeli barang jasa turun yang mana ini akan berimbas kepada sektor produsen penghasil barang. Tapi tidak berimbas langsung kepada NPL atau kredit yang bermasalah.

Inflasi berkaitan erat denga daya beli. Jika harga kebutuhan naik secara terus menerus maka akan terjadi penurunan daya beli yang disebabkan karena nilai penghasilan yang turun. Hal ini akan berpengaruh terhadap volume penjualan yang akan berpengaruh terhadap pendapatan produsen begitu juga akan menurunkan jumlah keuntungan yang diperoleh kepada produsen. Pada jangka panjang hal ini berdampak 
terhadap kredit perbankan.Inflasi dan daya beli tidak secara langsung mempengaruhi NPL. Hal ini sejalan dengan hasil regresi yang ditunjukkan.

Berdasarkan hasil regresi diatas maka dinyatakan bahwa inflasi tidak memiliki pengaruh pada NPL. Hal ini sesuai dan mendukung penelitian yang dilakukan oleh Sri Muljaningsih dan Riska Dwi Wulandari yang berjudul Analisa pengaruh inflasi, Suku bunga SBI dan GDP terhadap NPL bank umum di indonesia periode 2013-2016.

\section{KESIMPULAN DAN SARAN}

Hasil penelitian menyatakann bahwasannya dari hasil uji regresi secara parsial pada tingkat signifikansi 0,05 adalah : (a) CAR berpengaruh positif signifikan terhadap NPL, (b) LDR berpengaruh negatif signifikan terhadap NPL (c) BOPO berpengaruh positif signifikan terhadap NPL (d) Ukuran perusahaan berpengaruh terhadap NPL, (e) Suku bunga SBI tidak berpengaruh terhadap NPL, (f) Daya beli tidak berpengaruh terhadap NPL dan (g) Inflasi tidak berpengaruh terhadap NPL.

Hasil uji secara simultan, maka hasilnya CAR,LDR,BOPO, Ukuran perusahaan, GDP, Inflasi dan suku bunga SBI berpengaruh signifikan terhadap NPL.

Bagi lembaga perbankan, melihat dari hasil penelitian diatas faktor yang berpengaruh terhadap NPL perbankan lebih banyak faktor dari dalam perusahaan, akan tetapi bukan berarti faktor luar perusahan tidak berpengaruh terhadap NPL. Faktor luar juga berpengaruh terhadap NPL akan tetapi tidak secara langsung. Oleh sebab itu lembaga perbankan harus benar hati dalam mengelola faktor dalam yang dimaksud seperti CAR,LDR,BOPO dan ukuran perusahaan agar lonjakan kredit macet bisa diatasi. Dagi peneliti berikutnya adalah jika penelitia berikutnya mau meneliti mengenai faktor yang berpengaruh terhadap NPL sebaiknya menambahkan faktor lain selain faktor yang diteliti pada penelitian ini seperti variabel sistem pengendalian intern kredit perbankan, nilai tukar dan lain-lain yang kira-kira bisa mempengaruhi NPL perbankan.

\section{DAFTAR PUSTAKA}

Kasmir, Dasar-dasar perbankan, PT Raja Grafindo Persada, Jakarta , tahun 2006,

Kuncoro, $M$ dan Suhardjono, BPFE, Yogyakarta, tahun 2002

Sastradipoetra, K, Manajemen Perbankan, Kappa Sigma, Bandung, Tahun 2004

Sugiyono, Metode Penelitian Bisnis, Alfabeta, bandung tahun 2016

Andreani Caroline Barus, dkk, Analisis Faktor yang Mempengaruhi Non Performing Loan Pada Bank Umum di indonesia, https://mikroskil.ac.id

Ariq fikria niagasi, Pengaruh LDR, Bank size, BI rate dan Exchange rate terhadap NPL studi empiris pada perbankan yang terdaftar di BEI tahun 2015 - 2018, Prosiding 2nd Business and economic conference in utilizing of modern technology, ISSN 2662-9404

KM Suli astrini, dkk, Pengaruh CAR,LDR dan bank Size terhadap NPL pada Lembaga Perbankan yang terdaftar di BEI, https://ejournal.undiksha.ac.id

Lia Ryzkita, M.Jusmansyah, Analisis Pengaruh Rasio CAR, LDR dan BOPO Terhadap NPL Studi Empirik Pada Bank Swasta Nasional Periode 2007-2010, https://journal.budiluhur.ac.id

Misra,B.M,Sarat Dhal, 2010, Pro cyslical management of non performing loans by the indian public sector bank, BIS asian Research papers, june 2010

Ranjan, Rajiv dan Sarat candra dhal,2003, Non performing loan and terms of creditof public sector banks in 


\section{Jurnal Ilmiah Ekonomi dan Bísnis}

Vol. 18. No.2,September 2021 : 183-188

EISSN : $2442-9813$

ISSN : $1829-9822$

india : an emperical Assesment" reserve bank of india occasional papers vol 24. No 3.

Sri Muljaningsih dan Riska Dwi Wulandari, Analisa Pengaruh Inflasi, Suku bunga SBI dan GDP terhadap NPL pada bank umum di Indonesia periode tahun 20132016, Oeconomicus Journal of Economics,

https://doi.org/10.15642/oje.2019 .3.2.153-176

Sukesi Marlina, Analisis pengaruh GDP, Inflasi dan BI rate terhadap NPL suatu studi pada bank umum yang terdaftar di BEI periode 2013 - 2018, https://ummg.ac.id 